\title{
Profile Of Phycisal Activity, Physical Fitness, and BMI Students of Senior High School in Surabaya
}

\author{
Irmantara Subagio ${ }^{1}$, Setiyo Hartoto ${ }^{2}$ \\ \{Irmantarasubagio@unesa.ac.id ${ }^{1}$, Setiyohartoto@unesa.ac.id² \\ Universitas Negeri Surabaya, Surabaya, Indonesia ${ }^{1,2}$
}

\begin{abstract}
Physical activity is related to healthy lifestyle and plays role in maintaining body shape and physical fitness. The participation rate in physical activity among school children in Indonesia in the last decade is decreasing. This research to measure physical activity and physical fitness as a diagnostic measure. The body composition needs to be measured through the Body Mass Index (BMI). This research is a type of survey. The physical activity questionnaire and MFT were used. The population are high school students in Surabaya and the sample using multistage random sampling. The results were: the nutritional status of students tended to be normal, gender did not affect nutritional status; the physical activity conditions of studedents tend to be active, lazy have higher physical activity than females; the physical fitness condition of students to be poor, males have a higher level of physical fitness than females; and there is an effect of nutritional status (BMI) and physical activity on physical fitness.
\end{abstract}

Keywords: Physical activity, physical fitness, nutritional status, student.

\section{Introduction}

The benefits of physical activity have been tested to bring a healthy life, maintain body shape, and physical fitness. The problem is, the participation rate in physical activity including sports among school-age children in Indonesia in the last decade has not shown a satisfactory number. However, there has never been a change in school programs that support increased student physical activity. It is as if they think that the students are in good school without having to provide treatment to increase physical activity. Even though the 2000-2010 survey created by Sport Development Index in Ministry of Sport (Menpora) on physical fitness, the level of physical fitness of school children in Indonesia tends to be in the low category. After that, there is no monitoring effort on physical activity and physical fitness. Indeed, high awareness is needed to be able to carry out regular physical activity in order to achieve a high degree of physical fitness. However, as if a sick person will never seek treatment before knowing that he is sick and a doctor will never give medication before diagnosing so that he knows the patient is sick, then the problem of physical activity and physical fitness needs to be measured so that students (patients) and teachers (doctors) can know the condition. to be able to immediately change the program to support increased physical activity and physical fitness. It is no secret that environmental conditions are getting worse, starting from pollution and ozone quality. Many think that pollution is a major factor in the occurrence of health problems in the form of problems in the respiratory tract. Asthma, is a problem that is considered to occur most often when someone is in high pollution air. However, based on the results of the 
study, the asthma of several groups of people in different environments, the level of pollution and ozone quality did not differ significantly, meaning that the pollution conditions and ozone quality did not support the occurrence of asthma. However, in cases of asthma, it turns out that children who do more physical activity and exercise have a lower risk of developing asthma [1]. Seeing the air condition in the city of Surabaya which is already too influenced by the surrounding industry and motor vehicles, pollution and local ozone which can indirectly contribute to lower the physical fitness of a person are increasingly being questioned [2]. In addition, the risk of degenerative diseases such as high blood pressure is common and exercise is one solution. Research shows that, moderate to upward physical activity can help lower the risk of depression in adults [3]. To avoid this, efforts are needed to provide programs for children to get used to regular physical activity so that they carry on for a lifetime.

Physical activity habits and sports in childhood can be used as predictors in adulthood. Those who are accustomed to physical activities and sports at a young age tend to continue these activities in adolescence and even adulthood [4]. In other literature, the choice of food and physical activity is the choice of ways to maintain an ideal body shape. Apart from health benefits, physical activity also provides physical benefits. Sufficient and regular physical activity can keep the body in a fit condition. Talking about a fit body, it is necessary to discuss physical fitness as a measure of a fit body condition. SDI survey results in 2005 show that the fitness level of students in Indonesia is 5.66\% in the good category and the rest are in the medium, poor, and even less category. Furthermore, in 2010 research conducted by the Center for Physical Quality of the Ministry of National Education stated that due to malnutrition and physical activity, the state of physical fitness of students nationally was $94 \%$ of students in a moderate, insufficient, and very deficient state, only $6 \%$ were in the good category. and very good [5]. In 2006, the SDI Team again measured the physical fitness of students in Indonesia, the results showed that the physical fitness of students in Indonesia was in the very good category, only $5.05 \%$, good $5.15 \%$, moderate $13.55 \%$, less $43,90 \%$ and less $37.40 \%$ [6]. Unfortunately, similar research is no longer carried out on a national scale. PJOK in schools is the only ideal way to provide education through physical means to form a healthy lifestyle. However, monitoring of this important variable is rarely done. Report cards still tend to bring up academic learning outcomes (psychomotor, cognitive, and affective) that do not reflect a healthy lifestyle through physical activity. For this reason, it is necessary to hold monitoring of the core variables in the efforts of PJOK according to their function. Evaluation system for treatment that is carried out to increase physical activity so that changes that occur due to treatment can be properly monitored and followed up immediately. similar research is no longer carried out on a national scale. PJOK in schools is the only ideal way to provide education through physical means to form a healthy lifestyle. However, monitoring of this important variable is rarely done. Report cards still tend to bring up academic learning outcomes (psychomotor, cognitive, and affective) that do not reflect a healthy lifestyle through physical activity. For this reason, it is necessary to hold monitoring of the core variables in the efforts of PJOK according to their function. Evaluation system for treatment that is carried out to increase physical activity so that changes that occur due to treatment can be properly monitored and followed up immediately. similar research is no longer carried out on a national scale. PJOK in schools is the only ideal way to provide education through physical means to form a healthy lifestyle. However, monitoring of this important variable is rarely done. Report cards still tend to bring up academic learning outcomes (psychomotor, cognitive, and affective) that do not reflect a healthy lifestyle through physical activity. For this reason, it is necessary to hold monitoring of the core variables in the efforts of PJOK according to their function. Evaluation system for treatment that is carried out to increase physical activity so 
that changes that occur due to treatment can be properly monitored and followed up immediately. PJOK in schools is the only ideal way to provide education through physical means to form a healthy lifestyle. However, monitoring of this important variable is rarely done. Report cards still tend to bring up academic learning outcomes (psychomotor, cognitive, and affective) that do not reflect a healthy lifestyle through physical activity. For this reason, it is necessary to hold monitoring of core variables in the efforts of PJOK according to their function. Evaluation system for treatment that is carried out to increase physical activity so that changes that occur due to treatment can be properly monitored and followed up immediately. PJOK in schools is the only ideal way to provide education through physical means to form a healthy lifestyle. However, monitoring of this important variable is rarely done. Report cards still tend to bring up academic learning outcomes (psychomotor, cognitive, and affective) that do not reflect a healthy lifestyle through physical activity. For this reason, it is necessary to hold monitoring of the core variables in the efforts of PJOK according to their function. Evaluation system for treatments that are carried out to increase physical activity so that changes that occur due to treatment can be properly monitored and followed up immediately. and affective) which does not reflect a healthy lifestyle through physical activity. For this reason, it is necessary to hold monitoring of core variables in the efforts of PJOK according to their function. Evaluation system for treatment that is carried out to increase physical activity so that changes that occur due to treatment can be properly monitored and followed up immediately. and affective) which does not reflect a healthy lifestyle through physical activity. For this reason, it is necessary to hold monitoring of core variables in the efforts of PJOK according to their function. Evaluation system for treatment that is carried out to increase physical activity so that changes that occur due to treatment can be properly monitored and followed up immediately.

\section{Literature review}

\subsection{Physical activity through PJOK}

Physical activity is the key to achieving a healthy life through an active lifestyle. The results showed that physical activity can reduce the risk of all causes of death, including reducing the risk of being overweight, reducing depressive symptoms, and improving the quality of life associated with being overweight over a longer period of time [3], [7]. These results explain that, physical activity carried out regularly and sufficiently can reduce the impact of a person's poor health condition. In order to become a lifestyle, physical activity needs to be accustomed to from an early age. The results showed that activity habits at an early age can be a predictor of exercise habits and physical activity in adulthood [4]. Therefore, promotion of physical activity to school-age children is important so that they have active habits so that they can carry it throughout their lives. As a place for children to learn, school is an ideal area for habituating physical activity [8]. Where within its scope there is early childhood which is easily controlled in terms of time and place. For this reason, PJOK as the only subject that utilizes physical activity as a learning medium is very strategic in achieving these goals. However, CHD in schools alone is not enough to have a significant impact on increasing physical activity, a special program is needed so that physical activity can be increased [9] and even physical fitness can be improved [10]. However, regardless of the form of the program applied. 


\subsection{Physical fitness and Body Mass Index}

There is no other way, physical fitness can be obtained through physical exercise systematically and progressively [6]. Research on physical fitness has been carried out for a long time, including many efforts made to improve physical fitness through physical activity. VO2Max is a measure that can be used to determine whether someone is said to be fit or not [12]. For this reason, PJOK as a vehicle for student movement must provide various activities that support increased physical fitness. The results showed that CHD can have an impact on children who are less sociable (isolated / anti-social) to become sociable in programs to increase physical activity [13]. The next issue that is no less important to discuss is the condition of the student body composition. Obesity is one of the factors that increase the risk of death [14]. One of the factors in the occurrence of obesity is the lower rate of participation of a person in physical activity. Many people who use their spare time to be lazy tend to have a habit of eating unhealthy and excessive food. The use of free time for physical activity is very important. It is not easy to change the habit of using leisure time to relax into physical activity. It needs a systematic program and high motivation so that this can happen [15]. PJOK in schools, is the answer to making successful creation, implementation, and monitoring of physical activity programs for students to get used to and carried away until they are adults. One of the factors in the occurrence of obesity is the lower rate of participation of a person in physical activity. Many people who use their spare time to be lazy tend to have a habit of eating unhealthy and excessive food. The use of free time for physical activity is very important. It is not easy to change the habit of using leisure time to relax into physical activity. It needs a systematic program and high motivation so that this can happen [15]. PJOK in schools, is the answer to making successful creation, implementation, and monitoring of physical activity programs for students to get used to and carried away until they are adults. One of the factors in the occurrence of obesity is the lower rate of participation of a person in physical activity. Many people who use their spare time to be lazy tend to have a habit of eating unhealthy and excessive food. The use of free time for physical activity is very important. It is not easy to change the habit of using leisure time to relax into physical activity. It needs a systematic program and high motivation so that this can happen [15]. PJOK in schools, is the answer to making successful creation, implementation, and monitoring of physical activity programs for students to get used to and carried away until they are adults. Many people who use their spare time to be lazy tend to have a habit of eating unhealthy and excessive food. The use of free time for physical activity is very important. It is not easy to change the habit of using leisure time to relax into physical activity. It needs a systematic program and high motivation so that this can happen [15]. PJOK in schools, is the answer to making successful creation, implementation, and monitoring of physical activity programs for students to get used to and carried away until they are adults. Many people who use their spare time to be lazy tend to have a habit of eating unhealthy and excessive food. The use of free time for physical activity is very important. It is not easy to change the habit of using leisure time to relax into physical activity. It needs a systematic program and high motivation so that this can happen [15]. PJOK in schools, is the answer to making successful creation, implementation, and monitoring of physical activity programs for students to get used to and carried away until they are adults. It needs a systematic program and high motivation so that this can happen [15]. PJOK in schools, is the answer to making successful creation, implementation, and monitoring of physical activity programs for students to get used to and carried away until they are adults. It needs a systematic program and high motivation so that this can happen [15]. PJOK in schools, is the answer to making successful creation, 
implementation, and monitoring of physical activity programs for students to get used to and carried away until they are adults.

\section{Research Methods}

This research is included in the type of survey. Conducted within the scope of the city of Surabaya in accordance with the distribution area, namely the western, central, southern, eastern and northern regions.

\subsection{Subject}

A total of 60,487 high school students in the city of Surabaya $(27,482$ boys and 33,005 girls) became the study population. The selection of subjects as samples was carried out by means of multistage random sampling, which is a combination of stratified random sampling and cluster sampling. An illustration of the sampling process can be done using the sequence as shown in Figure 1 as follows.

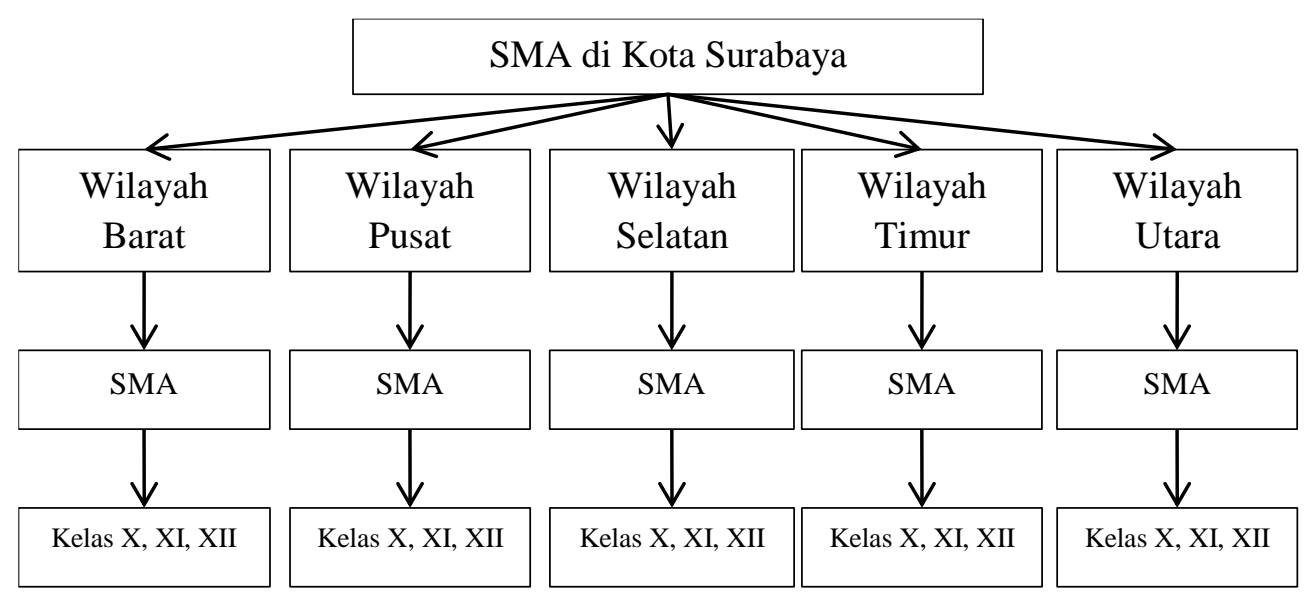

Fig. 1. Sample selection method

Sample selection will be carried out in 5 regions by choosing one school randomly, then randomly selected male and female students from each grade level according to the proportion of the number of students from each region. The proportion is determined by the percentage of students in each area compared to the population. The percentage in each region is then multiplied by the target sample size to be selected. The total sample to be selected is 500 students[16], [17].

\subsection{Instrumentation}

The instruments used to measure each variable are as follows.

1. Physical activity $=$ exercise habits questionnaire developed by the Sport Development Index team [6].

2. Physical fitness = using the Multistage Fitness Test (MFT) [6], [12].

3. Body Mass Index (BMI) = using a measuring tool for body weight and height [18]. 


\subsection{Procedure}

The research will begin with licensing the education office through Bakesbangpol. Furthermore, it is forwarded to the school principals according to the results of the sample takers. Data collection will be carried out by the team by means of tests and questionnaires. Height and weight measurements will be carried out prior to the implementation of the MFT. Physical fitness will be identified by MFT, which is running back and forth according to the standard cue as far as $20 \mathrm{~m}$. After completing the MFT, students are asked to fill out a questionnaire.

\subsection{Analysis}

Data analysis was carried out by means of descriptive and correlation. The choice of correlation type (parametric or non-parametric) will be determined according to the data and the form of data distribution formed after the data is collected.

\section{Result and discussion}

\subsection{Descriptive statistics and comparison of physical fitness, physical activity, and BMI by region}

Below is a comparison of physical fitness, physical activity, and BMI by region. The analysis used was ANOVA, the results of the analysis can be seen in table 1 as follows.

Table 1. Comparison physical fitness, physical activity, and BMI by region

\begin{tabular}{llllllllll}
\hline Variable & Territory & $\mathbf{N}$ & Mean & SD & Min & Max & F & p & Ket \\
\hline BMI & Southern (1) & 91 & 21.92 & 4.02 & 15.6 & 39.4 & 4.13 & 0.003 & $1>3$ \\
& Central (2) & 102 & 21.27 & 4.22 & 14.2 & 33.9 & & & \\
& North (3) & 71 & 19.33 & 4.76 & 12.7 & 44.7 & & & \\
& Western (4) & 88 & 20.07 & 5.39 & 0.0 & 35.6 & & & \\
& Eastern (5) & 101 & 20.92 & 4.32 & 12.8 & 37.2 & & & $1>3$ \\
Physical & Total & 453 & 20.79 & 4.60 & 0.0 & 44.7 & & & $2<5$ \\
Activity & Southern (1) & 91 & 6.88 & 3.05 & 0.0 & 15.0 & \multirow{2}{*}{0} & & \\
& Central (2) & 102 & 5.79 & 3.22 & 0.0 & 12.0 & & & $4<5$ \\
& North (3) & 71 & 4.56 & 3.97 & 0.0 & 12.0 & & & \\
& Western (4) & 88 & 5,53 & 3.97 & 0.0 & 14.0 & & & \\
& Eastern (5) & 101 & 7.42 & 3.15 & 0.0 & 14.0 & & & $1>2 ; 1>3$ \\
& Total & 453 & 6.13 & 3.58 & 0.0 & 15.0 & & & $1<4 ; 1>5$ \\
\hline
\end{tabular}




\begin{tabular}{lllllll}
\hline North (3) & 71 & 25.38 & 5.87 & 19.1 & 44.9 & $2<4 ; 3<4$ \\
Western (4) & 88 & 34.97 & 8.89 & 22.6 & 59.0 & $4>5$ \\
Eastern (5) & 101 & 26.26 & 5.65 & 18.1 & 42.1 & \\
Total & 453 & 28.29 & 7.53 & 18.1 & 59.0 & \\
\hline
\end{tabular}

Based on table 1 above, it can be explained as follows.

The highest BMI is the BMI of students in the southern region. Significant differences occur in the southern and northern regions. However, others are stated to be the same. This means that in general the nutritional status of students in the city of Surabaya is the same, except for the southern and northern regions.

Physical activity - students in the city of Surabaya are stated to be diverse / different. The physical activity values are sorted from the highest to the lowest, are the East $(\mathrm{N}=101, \mathrm{M}=$ $7.42, \mathrm{SD}=3.15)$, the South $(\mathrm{N}=91, \mathrm{M}=6.88, \mathrm{SD}=3,05)$, the Central Region $(\mathrm{N}=102, \mathrm{M}=$ $5.79, \mathrm{SD}=3.22)$, the West $(\mathrm{N}=88, \mathrm{M}=5.53, \mathrm{SD}=3.97)$, and the North $(\mathrm{N}=71, \mathrm{M}=4.56$, $\mathrm{SD}=3.97$ ).

Physical fitness - students in the city of Surabaya are stated to be various / different. The physical fitness values in order from the lowest to the highest are the Central region $(\mathrm{N}=102$, $\mathrm{M}=25.05, \mathrm{SD}=4.48)$, the North region $(\mathrm{N}=71, \mathrm{M}=25.38, \mathrm{SD}=5,87)$, the East $(\mathrm{N}=101$, $\mathrm{M}=26.26, \mathrm{SD}=5.65)$, the South $(\mathrm{N}=91, \mathrm{M}=29.97, \mathrm{SD}=7.34)$, the West $(\mathrm{N}=88, \mathrm{M}=$ $34.97, \mathrm{SD}=8.89$ ).

\subsection{Differences in physical activity, nutritional status, and physical fitness based on gender}

It is important to pay attention to the gender variable because of the different habits and body composition. It is necessary to examine differences in physical activity, nutritional status and physical fitness based on gender.

Following are the results of the analysis of differences in nutritional status based on gender (table 2).

Table 2. Differences in nutritional status by gender

\begin{tabular}{llllllll}
\hline & & \multicolumn{2}{c}{ Gender } & Total & X2 & df & $\mathrm{p}$ \\
\cline { 3 - 5 } & & Man & Women & & & & \\
\hline BMI category & Very thin & 40 & 30 & 70 & 8.59 & 4 & 0.07 \\
& Thin & 31 & 33 & 64 & & & \\
& Normal & 106 & 143 & 249 & & & \\
& Fat & 19 & 12 & 31 & & & \\
\cline { 4 - 6 } Total & Obesity & 22 & 17 & 39 & & & \\
\hline
\end{tabular}

Based on table 2 above, two things can be explained as follows. 
a. It can be concluded that the frequency in the NORMAL category shows a trend in the nutritional status of students. This means that the nutritional status of students in Surabaya tends to be NORMAL.

b. The different test results show that the value of Chi-Square, $\mathrm{X}^{2}(4, \mathrm{~N}=453)=8.59, \mathrm{p}=$ 0.07 . This means that there is no difference in nutritional status between male and female students in the city of Surabaya.

Furthermore, the differences in physical activity based on gender are explained. The results of the analysis can be seen in table 3 as follows.

Table 3. Differences in physical activity based on gender

\begin{tabular}{|c|c|c|c|c|c|c|c|}
\hline & & \multicolumn{2}{|c|}{ Gender } & \multirow{2}{*}{ Total } & \multirow{2}{*}{$\mathrm{X} 2$} & \multirow{2}{*}{$\mathrm{df}$} & \multirow{2}{*}{$\mathrm{p}$} \\
\hline & & Man & Women & & & & \\
\hline \multirow{4}{*}{$\begin{array}{l}\text { Physical } \\
\text { Activity } \\
\text { Category }\end{array}$} & Passive & 23 & 55 & 78 & & & \\
\hline & Less Active & 32 & 52 & 84 & & & \\
\hline & Active & 133 & 116 & 249 & & & \\
\hline & Very active & 30 & 12 & 42 & & & \\
\hline Total & & 218 & 235 & 453 & & & \\
\hline
\end{tabular}

Based on table 3 above, two things can be explained as follows.

a. It is concluded that the frequencies in the ACTIVE AND VERY ACTIVE categories indicate a tendency for the physical activity conditions of students. This means that students in Surabaya tend to be ACTIVE.

b. Different test results show that the value of Chi-Square, $X^{2}(3, N=453)=26.17, p=0.00$. This means that there are differences in activity between male and female students in the city of Surabaya. Male students tend to be more active than girls.

Furthermore, the differences in physical fitness based on gender are explained. The results of the analysis can be seen in table 4 as follows.

Table 2. Differences in physical fitness differences based on gender

\begin{tabular}{lllllll}
\hline & & \multicolumn{3}{c}{ Gender } & & \\
& & Man & Women & & X2 df & p \\
\hline Physical & Passive & 23 & 55 & 78 & \\
Activity & Less Active & 32 & 52 & 84 & \\
Category & Active & 133 & 116 & 249 & \\
& Very active & 30 & 12 & 42 & \\
\multirow{2}{*}{ Total } & & 218 & 235 & 453 & \\
\hline
\end{tabular}

Based on table 4 above, two things can be explained as follows. 
a. Based on the table, it can be concluded that the frequencies in the VERY BAD AND BAD categories indicate a tendency for students to be fresh. This means that students in Surabaya tend to have BAD fitness.

b. Different test results show that the value of Chi-Square, $\mathrm{X}^{2}(6, \mathrm{~N}=453)=52.05, \mathrm{p}=0.00$. This means that there are differences in fitness between male and female students in the city of Surabaya. Male students tend to be more fit than girls.

\subsection{The relationship between physical fitness and physical activity}

Next, it is necessary to analyze the relationship between physical fitness and physical activity. The results of the analysis can be seen in table 5 as follows.

Table 3. The relationship between physical fitness and physical activity

\begin{tabular}{llllllll}
\hline & $\mathrm{N}$ & Minimum & Maximum & Mean & SD & $\mathrm{r}$ & $\mathrm{p}$ \\
\hline Physical Activity & 453 & 0 & 15 & 6.13 & 3.58 & \multirow{2}{*}{$288 * *$} & \multirow{2}{*}{000} \\
VO2Max & 453 & 18.1 & 59.0 & 28.29 & 7.53 & \multirow{2}{*}{, $288 *$} \\
\hline
\end{tabular}

Based on table 5 above, two things can be explained as follows.

a. Based on the table, it can be explained that the lowest score for students' physical activity is 0 (not doing physical activity regularly) and the highest is 15 , the average value is 6.13 \pm 3.58 . The lowest physical fitness score was 18.1 (very poor) and the highest was 59.0 (special) with an average of $28.29 \pm 7.53$ (mean).

b. The results of the correlation test showed that there was a significant relationship between physical activity and students' physical fitness, $\mathrm{r}(453)=0.288, \mathrm{p}=0.000$.

\subsection{Relationship between physical fitness and nutritional status and physical activity}

Ancova is used to analyze the relationship between the three variables. The results of the analysis can be seen in table 6 as follows.

Dependent Variable: VO2Max

Table 4. Relationship between physical fitness and nutritional status and physical activity

\begin{tabular}{lllllll}
\hline Source & Type III & df & Mean Square & F & Sig. & Partial \\
\hline Corrected Model & $3638 \mathrm{a}$ & 19 & 191 & 3.77 &, 000 &, 142 \\
Intercept & 128431 & 1 & 128431 & 2529 &, 000 &, 854 \\
BMI & 588 & 4 & 147 & 2.89 &, 022 &, 026 \\
Physical Activity & 1428 & 3 & 476 & 9.37 &, 000 &, 061 \\
BMI * Physical & 219 & 12 & 18.2 &, 359 &, 977 &, 010 \\
Activity & 21990 & 433 & 50.8 & & & \\
Error & 388086 & 453 & & & & \\
Total & 25628 & 452 & & & & \\
Corrected Total & & & & & & \\
\hline
\end{tabular}


a. $\mathrm{R}$ Squared =, 142 (Adjusted R Squared $=, 104)$

b. Computed using alpha $=.05$

Based on table 6 above, two things can be explained as follows.

1. Based on the ANCOVA test (between-subjects factor: nutritional status (BMI); covariate: physical activity, there is an effect of nutritional status (BMI) on physical fitness. F (4, $433)=2.89, p=0.02$, there is an effect of physical activity on physical fitness $\mathrm{F}(3,433)$ $=9.37, \mathrm{p}=0.00$. The interaction between nutritional status and physical activity was not significant, $\mathrm{F}(12,433)=0.359, \mathrm{p}=0.977$.

2. So it can be concluded that physical fitness is significantly influenced by physical activity and nutritional status.

\section{Conclusions and suggestions}

Based on the results and discussion of the research, it can be concluded that (1) The nutritional status of students in the city of Surabaya tends to be NORMAL, gender does not affect nutritional status; (2) The physical activity conditions of students in the city of Surabaya tend to be active, males have higher physical activity than females; (3) The physical fitness condition of students in the city of Surabaya tends to be poor, males have a higher level of physical fitness than females; and (4) There is an effect of nutritional status (BMI) and physical activity on physical fitness. So it can be suggested that although the nutritional status tends to be normal, students in nutritional status are still obese, so it is necessary to regulate diet and physical activity to control nutritional status. The condition of the physical activity of female students is lower than that of boys, for this reason, PJOK learning needs to be designed to increase the proportion of physical activity for women. The physical fitness of students in the city of Surabaya tends to be poor, based on the results of this study, it is necessary to maintain the condition of nutritional status and increase physical activity so that physical fitness can be improved.

\section{References}

[1] "Ozone, Physical Activity, and Asthma," Eur. J.Pediatr., Vol. 161, no. 12, pp. 691-691, Dec. 2002.

[2] MW Akhmad, AV Vitianingsih, and TA Wijaya, "Mapping of Air Pollution Levels in the City of Surabaya Based on Android," Inform, vol. 1, no. 1, 2016.

[3] AO Werneck, AL Oyeyemi, and DR Silva, "Physical activity and depression: is $150 \mathrm{~min} /$ week of moderate to vigorous physical activity a necessary threshold for decreasing risk of depression in adults? Different views from the same data, "Soc. Psychiatry Psychiatr. Epidemiol., Vol. 53, no. 3, pp. 323-324, Mar. 2018.

[4] M. Bélanger et al., "Number of years of participation in some, but not all, types of physical activity during adolescence predicts the level of physical activity in adulthood: Results from a 13-year study," Int. J. Behav. Nutr. Phys. Act., Vol. 12, no. 1, p. 76, Dec. 2015.

[5] TC Mutohir, "Physical Education and Sports for Character Development. The material was delivered at the National Physical Education and Sports Workshop and Conference on 27 - 28 September 2011. Bandung: Postgraduate School of Pe Study Program, "in Workshop and National Conference on Physical Education and Sports, 2011, no. September 27-28.

[6] A. Mutohir, T. Ch. and Maksum, Sport Development Index: Concepts, Methodologies, and Applications. Jakarta: PT. Index, 2007. 
[7] SJ Dankel, JP Loenneke, and PD Loprinzi, "Health Outcomes about Physical Activity Status, Overweight / Obesity, and History of Overweight / Obesity: A Review of the WATCH Paradigm," Sport. Med., Vol. 47, no. 6, pp. 1029-1034, Jun. 2017.

[8] JF Sallis, TL McKenzie, MW Beets, A. Beighle, H. Erwin, and S. Lee, "Physical Education's Role in Public Health: Steps Forward and Backward Over 20 Years and HOPE for the Future," Res. Q. Exerc. Sport, vol. 83, no. 2, pp. 125-135, 2012.

[9] E. Powell, LA Woodfield, and AM Nevill, "Increasing physical activity levels in primary school physical education: The SHARP Principles Model," Prev. Med. Reports, vol. 3, pp. 7-13, Jun. 2016.

[10] JF Sallis, TL McKenzie, JE Alcaraz, B. Kolody, N. Faucette, and MF Hovell, "The effects of a 2year physical education program (SPARK) on physical activity and fitness in elementary school students," Am. J. Public Health, vol. 87, no. 8, pp. 1328-1334, 1997.

[11] SA Hoffman, JL Warnick, E. Garza, and B. Spring, "Physical activity: a synopsis and comment on 'community-wide interventions for increasing physical activity,"' Transl. Behav. Med., Vol. 7, no. 1, pp. 39-42, Mar. 2017.

[12] AH Ismail and DL Montgomery, "The effect of a four-month physical fitness program on a young and an old group matched for physical fitness," Eur. J. Appl. Physiol.Occup. Physiol., Vol. 40, no. 2, pp. 137-144, 1979.

[13] SJ dos Santos, CM Hardman, SSH Barros, C. da FBF Santos, and MVG de Barros, "Association between physical activity, participation in Physical Education classes, and social isolation in adolescents," J. Pediatr. (Rio. J)., Vol. 91, no. 6, pp. 543-550, Nov. 2015.

[14] J. Petrides, P. Collins, A. Kowalski, J. Sepede, and M. Vermeulen, "Lifestyle Changes for Disease Prevention," Prim. Care Clin. Off. Pract., Vol. 46, no. 1, pp. 1-12, Mar. 2019.

[15] AE Cox, AL Smith, and L. Williams, "Change in Physical Education Motivation and Physical Activity Behavior during Middle School, "J. Adolesc. Heal., Vol. 43, no. 5, pp. 506-513, Nov. 2008.

[16] R. V Krejcie and DW Morgan, "DETERMINING SAMPLE SIZE FOR RESEARCH ACTIVITIES," 1970.

[17] JE Bartlett, JW Kotrlik, and CC Higgins, "Organizational Research: Determining Organizational Research: Determining Appropriate Sample Size in Survey Research Appropriate Sample Size in Survey Research," 2001.

[18] "Kepmenkes No.1995 / Menkes / SK / XII / 2010 concerning Anthropometric Standards for Assessment of Children's Nutritional Status. " p. 4, 2010. 